\title{
Role of the Metal Surface on the Room Temperature Activation of the Alcohol and Amino Groups of $p$-Aminophenol
}

Nerea Ruiz del Árbol, Irene Palacio, Carlos Sánchez-Sánchez, Gonzalo Otero-Irurueta, José I. Martínez, Luis Rodríguez, David Serrate, Albano Cossaro, Paolo Lacovig, Silvano Lizzit, Alberto Verdini, Luca Floreano, José A. Martín-Gago, and María F. López*

Cite This: J. Phys. Chem. C 2020, 124, 19655-19665

Read Online

\section{ACCESS |}

Wll Metrics \& More

Article Recommendations

ABSTRACT: We present a comparative study of the roomtemperature adsorption of $p$-aminophenol ( $p$-AP) molecules on three metal surfaces, namely $\mathrm{Cu}(110), \mathrm{Cu}(111)$, and $\mathrm{Pt}(111)$. We show that the chemical nature and the structural symmetry of the substrate control the activation of the terminal molecular groups, which result in different arrangements of the interfacial molecular layer. To this aim, we have used in situ STM images combined with synchrotron radiation high-resolution XPS and NEXAFS spectra, and the results were simulated by DFT calculations. On copper, the interaction between the molecules and the surface is weaker on the (111) surface crystal plane than on the (110) one, favoring

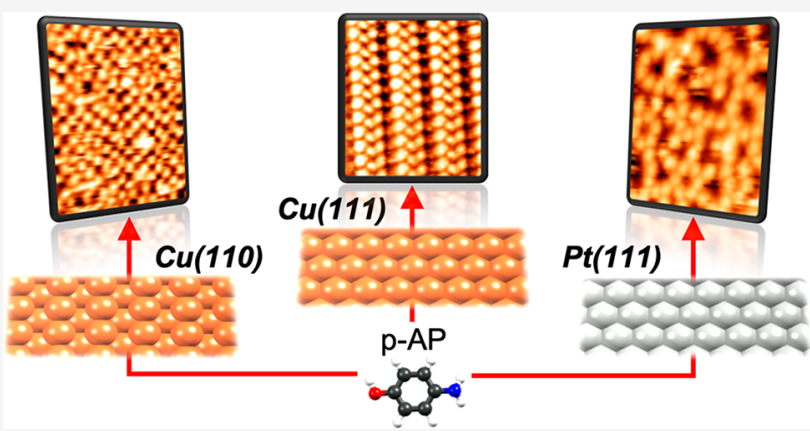
molecular diffusion and leading to larger ordered domains. We demonstrate that the $p$-AP molecule undergoes spontaneous dehydrogenation of the alcohol group to form phenoxy species on all the studied surfaces; however, this process is not complete on the less reactive surface, $\mathrm{Cu}(111)$. The Pt(111) surface exhibits stronger molecule-surface interaction, inducing a short-range ordered molecular arrangement that increases over time. In addition, on the highly reactive $\mathrm{Pt}(111)$ surface other chemical processes are evidenced, such as the dehydrogenation of the amine group.

\section{INTRODUCTION}

Surfaces have become a central issue not only in important technological and biological processes but also in the synthesis of a large number of $0 \mathrm{D}, 1 \mathrm{D}$, and $2 \mathrm{D}$ nanomaterials, which are versatile for a variety of functional applications. ${ }^{1-3}$ Moreover, in the past years, there have been increasingly rapid advances in the field of on-surface synthesis, which has been consolidated as a powerful tool for the development of novel low-dimensional materials. This synthesis strategy uses a bottom-up approach, which allows obtaining specific materials that are not possible to achieve by other routes. ${ }^{4-7}$ However, when thermally induced on-surface chemical reactions are used to synthesize a new product; a rational design of the precursor and the election of the most convenient surface will be crucial to target specific outcomes. This conceptual approach requires a thorough understanding of the as-deposited interactions of the molecular precursor with the surface. Once the precursor molecules are adsorbed on a surface, their spontaneous selfassembly usually takes place, ${ }^{8-10}$ forming stable structures, typically through noncovalent interactions. In this sense, the study of the adsorption behavior of the precursor molecules on a surface before inducing the covalent coupling reactions will contribute to understand the first stages of the bottom-up process. ${ }^{11}$ This adsorption mechanism will define the chemical reactivity of the precursor molecules on a specific surface determining the properties and the structure of the final outcome. ${ }^{12}$ To date, some studies have been already reported to demonstrate a different behavior of the same molecule adsorbed on different surfaces, highlighting the role of the surface in the process. Examples of this observed behavior are the cases of perylenetetracarboxylic dianhydride (PTCDA), benzene, and porphyrins, among others, in which different properties have been observed as a consequence of the different geometrical adsorptions. ${ }^{13-15}$

The diverse adsorption geometries emerge as a result of the balance of two interactions: molecule-surface and moleculemolecule. ${ }^{10}$ The molecule-surface interaction determines the chemistry of the system, as a surface-induced catalytic modification of the precursor can take place, even at room temperature (RT). This is the case of some hydroxyl moieties on $\mathrm{Pt}(111) .{ }^{16,17}$ Moreover, the local structural orientation of

Received: July 3, 2020

Revised: August 11, 2020

Published: August 12, 2020 
the molecules depends on these interactions. The moleculemolecule interaction allows formation of ordered patterns by self-assembly either by nonselective bonds, as electrostatic or van der Waals interaction, ${ }^{10,18}$ or by selective and directional linkages as hydrogen or metal-organic bonds. ${ }^{19,20}$ This preorganized layer can help to induce directionality of the reaction outcome. In summary, the molecule-surface interaction is mainly related to the energetics of the system, whereas the molecule-molecule one is affected by the kinetics. Therefore, when an organic molecule adsorbs on a catalytic surface, this surface induces an activation of the molecule forming a stable phase whose orientation, chemical nature, and adsorption geometry will be critical for a foreseeable next step involving a chemical reaction. ${ }^{10,11,21,22}$

The aim of this study is to investigate the influence of the different structure and reactivity of three metallic surfaces $(\mathrm{Cu}(110), \mathrm{Cu}(111)$, and $\mathrm{Pt}(111))$ on the adsorbed phases that are formed upon molecular deposition. As a model molecule, we have chosen $p$-aminophenol ( $p$-AP), which consists in a central benzene ring $(\mathrm{Ph})$ with two functional groups, an alcohol $(-\mathrm{OH})$ and an amine $\left(-\mathrm{NH}_{2}\right)$, in the para position. From the chemical point of view, the interest of this molecule lies on the rich reactivity of its aforementioned groups, which have been demonstrated to be easily activated on metal surfaces. It is also important to remark that this molecule presents a large dipole moment, which will govern molecular arrangement on low reactive surfaces. The election of the three different surfaces is not fortuitous. Two of them correspond to two different faces of $\mathrm{Cu}$ to study the effect of the atomic surface termination, while the third one, $\mathrm{Pt}(111)$, has been chosen given its different catalytic properties. The analysis and characterization have been performed by using a combination of different experimental surface techniques, such as scanning tunneling microscopy (STM), low-energy electron diffraction (LEED), near-edge X-ray absorption fine structure (NEXAFS), and X-ray photoelectron spectroscopy (XPS), and first-principles theoretical calculations. We show the chemical nature, the adsorption geometry, and the electronic properties of $p$-AP adsorbed on different surfaces and discuss the differences. This work highlights the different chemical behavior of the $p$-AP molecule upon absorption on the three different surfaces, which exhibit different nature or structural symmetry.

\section{EXPERIMENTAL AND THEORETICAL METHODS}

All experiments were performed in situ in different ultrahighvacuum (UHV) systems with a base pressure of $10^{-10} \mathrm{mbar}$. In all of them, $p$-AP molecules (Sigma-Aldrich, 99\% purity) were evaporated onto the different surfaces by spontaneous sublimation from a quartz crucible. That quartz container was located in a prechamber with an independent pumping system and a base pressure of $10^{-9}$ mbar. Before the evaporation procedure, all surfaces were cleaned by repeated cycles of $\mathrm{Ar}^{+}$sputtering and subsequent annealing at temperatures of 870,670 , and $1120 \mathrm{~K}$ for $\mathrm{Cu}(110)$, $\mathrm{Cu}(111)$, and $\mathrm{Pt}(111)$, respectively. In the case of the $\mathrm{Pt}(111)$ surface, the first annealing cycles were made under an oxygen atmosphere $\left(P_{\mathrm{O}_{2}}=1 \times 10^{-6} \mathrm{mbar}\right)$ to remove carbon contamination. LEED patterns, acquired with an OMICRON LEED model Spectaleed, allow both determining the cleanness of the samples before evaporating the $p$-AP molecules and exploring the molecular structures after evaporation.

The $p-\mathrm{AP} / \mathrm{Cu}(110), p-\mathrm{AP} / \mathrm{Cu}(111)$, and $p-\mathrm{AP} / \mathrm{Pt}(111)$ systems were obtained at room temperature by exposing the substrate to $p$-AP molecules for different times to procure different coverages. The multilayer phase, used for comparative purposes, was obtained by sublimation of the $p$-AP molecules on a $\mathrm{Cu}(110)$ surface at $-70{ }^{\circ} \mathrm{C}$ for $30 \mathrm{~min}$. This allows comparing the three $p$ - $\mathrm{AP} /$ surface systems with respect to the pristine $p$-AP.

STM measurements were performed at several UHV systems with different STM microscopes. For the case of $p$ $\mathrm{AP} / \mathrm{Cu}(110)$ and $p-\mathrm{AP} / \mathrm{Cu}(111)$ and the low coverage $p-\mathrm{AP} /$ Pt(111) samples, a RT-STM OMICRON microscope was used at a constant current mode while the high coverage $p$-AP/ $\mathrm{Pt}(111)$ sample was performed with a JT-STM SPECS microscope at $4.2 \mathrm{~K}$ and also at constant current mode. High-resolution XPS and NEXAFS experiments were performed at the Elettra Synchrotron in Trieste (Italy). The multilayer phase and the $p-\mathrm{AP} / \mathrm{Cu}(110)$ and $p-\mathrm{AP} / \mathrm{Cu}(111)$ systems were measured at the ALOISA beamline. For those samples, high-resolution XPS spectra were recorded at a grazing incidence of $4^{\circ}$ in normal emission geometry. We measured the $\mathrm{C} 1 \mathrm{~s}, \mathrm{~N} 1 \mathrm{~s}$, and $\mathrm{O} 1 \mathrm{~s}$ spectra using photon energies of 400, 500, and $650 \mathrm{eV}$, respectively, with a corresponding overall energy resolution of 140, 160, and 260 $\mathrm{meV}$. The binding energy scale was calibrated to the Fermi level. Polarization-dependent NEXAFS measurements were performed at the $\mathrm{C}$ K-shell ionization threshold in partial electron yield (PEY) by means of a channeltron with a retarding grid to reject low-energy secondary electrons. At ALOISA, the polarization was changed from transverse magnetic (closely p-polarization) to transverse electric ( $s$ polarization) by a $90^{\circ}$ sample rotation around the photon beam axis, while keeping the surface at a constant grazing angle of $6^{\circ}$. The XPS and NEXAFS of the $p$-AP/Pt(111) system were accomplished at the SuperESCA beamline. In this system, high-resolution XPS spectra were recorded at the C 1s, N 1s, and $\mathrm{O} 1 \mathrm{~s}$ regions by using photon energies of 370,480 , and $620 \mathrm{eV}$, respectively, and with energy resolution better than 50 $\mathrm{meV}$. The binding energy scale was calibrated to the Fermi level of the metal substrate. For $p-\mathrm{AP} / \mathrm{Pt}(111)$, polarizationdependent NEXAFS measurements were performed at $\mathrm{C} \mathrm{K}$ shell ionization threshold using two different angular configurations, corresponding to incidence angles of $20^{\circ}$ and $90^{\circ}$ with respect to the surface.

For all the first-principles calculations (structural optimization, computation of the electronic structure properties, and STM-imaging simulations) of the different $p$-AP/Cu interfaces in this study, density functional theory (DFT) was used by effectively combining the plane-wave and localized-basis-set schemes as implemented in the plane-wave QUANTUM ESPRESSO simulation package ${ }^{23}$ - used for the determination of the complex interface atomic geometry and for the analysis of the interfacial electronic properties-and in the localized basis-set FIREBALL simulation code ${ }^{24}$-employed for the STM-imaging simulations. This theoretical strategy has been already successfully adopted in a recent publication by our group (see further details on the theoretical methods in ref 22 and references therein).

To construct all the interfacial $p-\mathrm{AP} / \mathrm{Cu}$ models in this study, used as trial system geometries in the calculations, we have considered (i) a slab of four $\mathrm{Cu}(110)$ and $\mathrm{Cu}(111)$ 

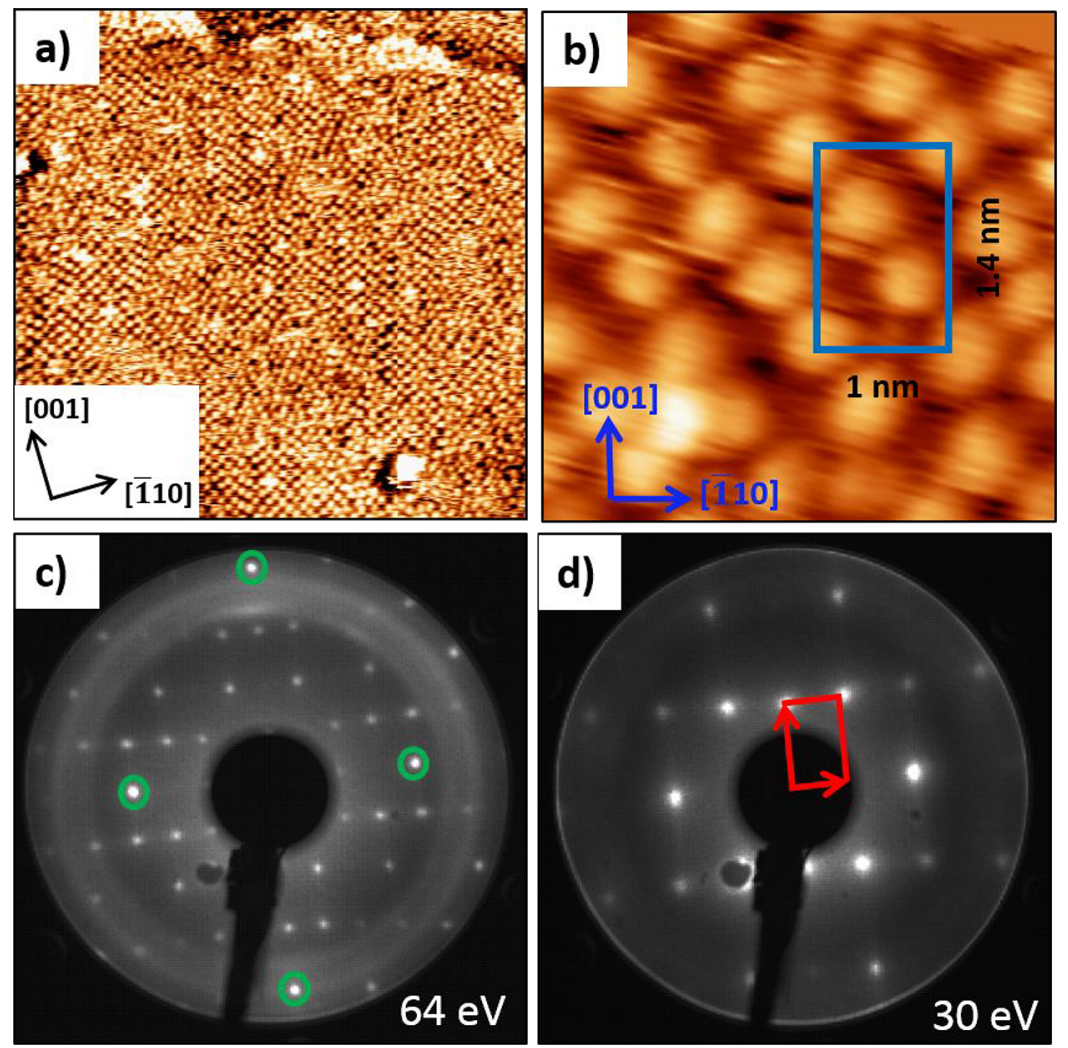

Figure 1. RT-STM images and LEED patterns after evaporation of $p$-AP molecules on a $\mathrm{Cu}(110)$ single crystal at room temperature. (a) Saturation coverage RT-STM constant-current image of $(30 \mathrm{~nm} \times 30 \mathrm{~nm})$ with $I_{\mathrm{t}}=0.39 \mathrm{nA}$ and $V_{\text {bias }}=1.5 \mathrm{~V}$. (b) RT-STM constant-current image of $(3.1 \mathrm{~nm}$ $\times 3.1 \mathrm{~nm}$ ) with $I_{\mathrm{t}}=0.15 \mathrm{nA}$ and $V_{\text {bias }}=1 \mathrm{~V}$. Blue rectangle marks the rectangular unit cell of the molecular arrangement. (c, d) LEED patterns with electron energies of 64 and $30 \mathrm{eV}$, respectively. The green circles indicate the spots of the $\mathrm{Cu}(110)$ substrate, and the red rectangle indicates the unit cell of the $p$-AP molecular arrangement.

physical layers, with a minimum distance of $\sim 20 \AA$ of vacuum between neighboring cells along the axis perpendicular to the surface, and (ii) full periodic boundary conditions representing infinite $\mathrm{Cu}$ surfaces. On-surface molecular adlayer lattices, initial location, and on-surface orientation of the molecules on the $\mathrm{Cu}$ surfaces, as starting-point interfaces to be fully DFTrelaxed, have been considered by following the experimental evidence as follows in the text.

To simulate STM images, we used a local-orbital formulation of DFT, as implemented in the FIREBALL code. $^{24}$ Tunneling currents for the STM images have been computed by using the Keldysh-Green function formalism, together with the first-principles tight-binding Hamiltonian obtained from the FIREBALL code, as explained in full detail elsewhere. $^{24-26}$ Our STM theoretical simulation approach includes a detailed description of the electronic properties of both the W-tip and the sample simultaneously (see ref 22 and references therein). All computed theoretical STM images have been obtained at constant-current scanning conditions, moving the $\mathrm{W}$ tip perpendicularly to the sample in each STM scanning step to search a preselected fixed value of the tunnel current, to mimic the experimental procedure.

\section{RESULTS AND DISCUSSION}

STM and LEED Analysis. Figures $1 \mathrm{a}$ and $1 \mathrm{~b}$ show two STM images of $p$-AP molecules deposited on $\mathrm{Cu}(110)$ at room temperature (RT). These images reveal a dominant pattern of molecular aggregation on the surface. In Figure 1b, the local arrangement of the $p$-AP ordered domains can be appreciated, where the blue rectangle highlights the rectangular unit cell (1 $\mathrm{nm} \times 1.4 \mathrm{~nm})$ of this superstructure. It should be pointed out that the STM images have shown no change of molecular contrast for occupied and unoccupied states as deduced by measuring at opposite STM bias polarities. RT-STM images show that the lateral size of the observed protrusions (around $0.4 \mathrm{~nm}$ ) is in fair agreement with the expected size of a single p-AP molecule (around $0.6 \mathrm{~nm}$ long and $0.3 \mathrm{~nm}$ wide). On the other hand, given the short separation between the $p$-AP molecules, it can be deduced that there exists some lateral interaction among them (see Figure $1 b$ ).

Figures 1c and 1d show the corresponding LEED patterns acquired at two different electron beam energies, which present a $(4 \times 4)$ unit. Some of the half-integer spots present low intensity which can be related to the structure factor. The green circles in Figure 1c mark the spots corresponding to the $\mathrm{Cu}(110)$ substrate, while the red rectangle in Figure 1d shows the unit cell of the molecular layer in the reciprocal space, corresponding to the blue rectangle of Figure $1 \mathrm{~b}$ in the real space.

Figure 2 shows three STM images recorded after deposition on the $\mathrm{Cu}(111)$ surface held at $370 \mathrm{~K}$ as well as the corresponding LEED pattern. It is noticed that upon deposition at RT on this surface the molecular mobility was so high that STM images could not be recorded. As it will be discussed later, the increase of temperature from RT to $370 \mathrm{~K}$ favors chemical processes that stabilize the molecules into ordered domains. As it can be seen in Figure 2, the molecular overlayer is characterized by a striped pattern. By carefully 

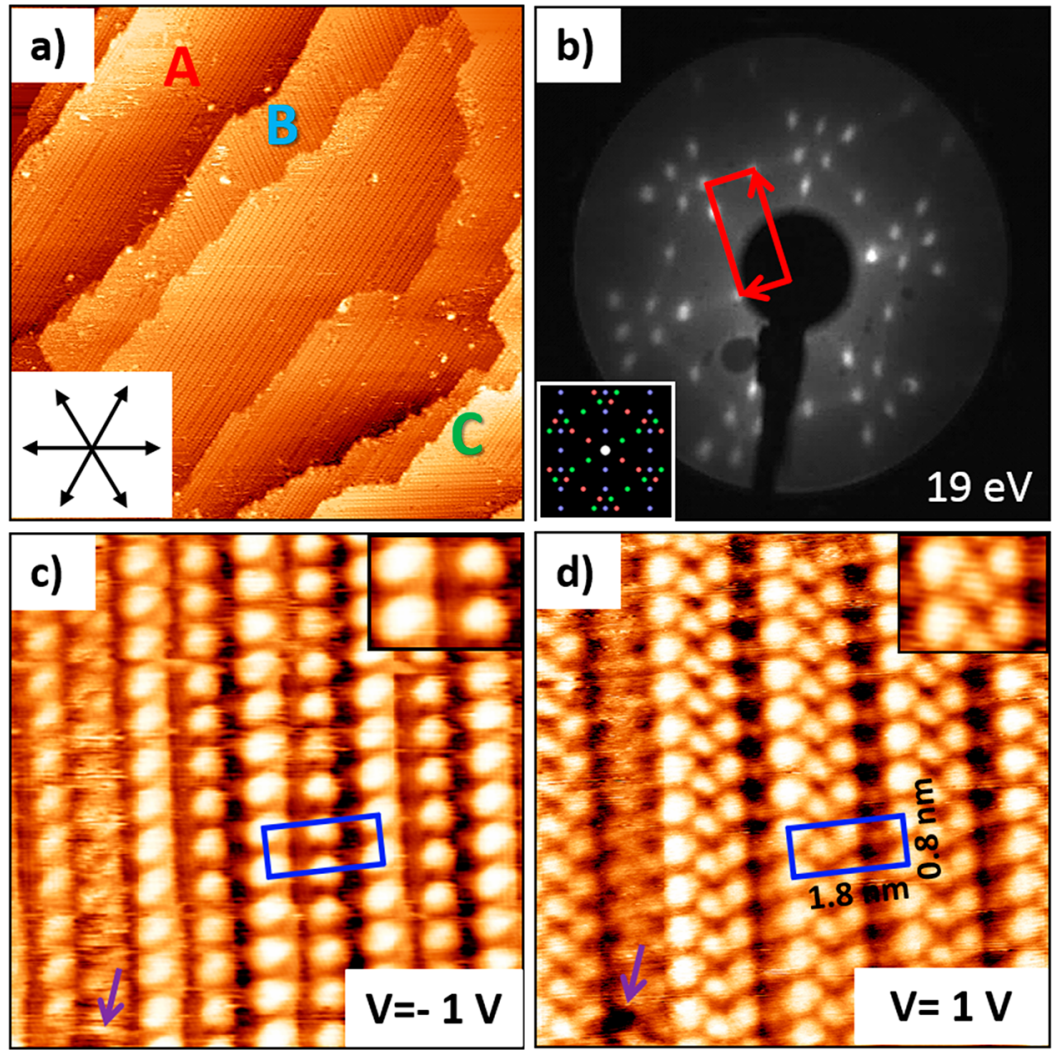

Figure 2. RT-STM images and LEED pattern after evaporation of a full monolayer of $p$-AP molecules on a Cu(111) surface at $370 \mathrm{~K}$. (a) RT-STM constant-current image of $(100 \mathrm{~nm} \times 100 \mathrm{~nm})$ with $I_{\mathrm{t}}=0.39 \mathrm{nA}$ and $V_{\text {bias }}=-1.5 \mathrm{~V}$. The inset shows the main crystallographic directions of the $\mathrm{Cu}(111)$ substrate. (b) LEED pattern at $19 \mathrm{eV}$, with the rectangular unit cell in red. The inset shows the simulated LEED pattern. (c, d) Occupied and unoccupied RT-STM constant-current images of $(8 \mathrm{~nm} \times 8 \mathrm{~nm})$ with $I_{\mathrm{t}}=0.03 \mathrm{nA}$ and different sample bias, respectively. The rectangular unit cell of the molecules is superimposed in blue. The insets show a detail of the structure for occupied $\left(V_{\text {bias }}=-1 \mathrm{~V}\right)$ and unoccupied states $\left(V_{\text {bias }}=1\right.$ V).
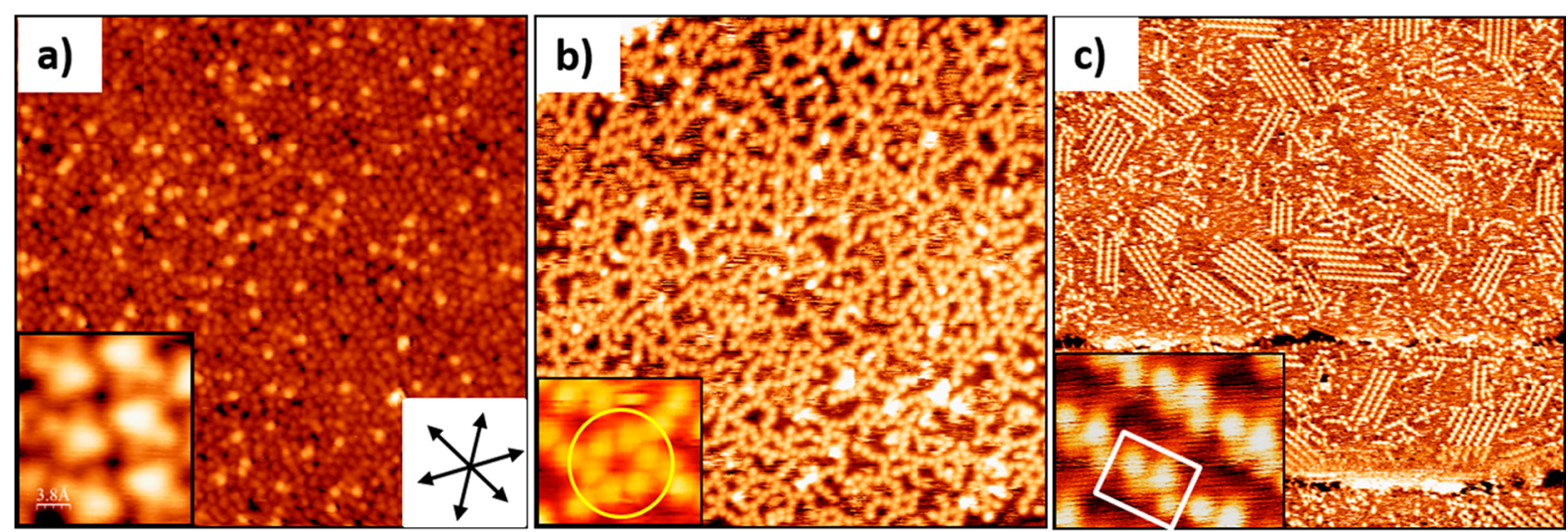

Figure 3. STM images for high (a) and intermediate (b, c) coverage of $p$-AP molecules on $\mathrm{Pt}(111)$ at RT recorded at constant current. (a) LTSTM image $(30 \mathrm{~nm} \times 30 \mathrm{~nm}) \cdot I_{\mathrm{t}}=0.04 \mathrm{nA}$ and $V_{\text {bias }}=1.2 \mathrm{~V}$. The right inset exhibits the main crystallographic directions of Pt $(111)$ while the left one shows a $(1.9 \mathrm{~nm} \times 2.1 \mathrm{~nm})$ zoom of single ordered $p$-AP molecules recorded with $I_{\mathrm{t}}=0.1 \mathrm{nA}$ and $V_{\text {bias }}=0.6 \mathrm{~V}$. (b) RT-STM overview image $(50 \mathrm{~nm} \times 50 \mathrm{~nm}) . I_{\mathrm{t}}=0.04 \mathrm{nA}$ and $V_{\text {bias }}=1.1 \mathrm{~V}$. The inset shows a zoom of the image $(10 \mathrm{~nm} \times 10 \mathrm{~nm})$. (c) RT-STM overview image $(75 \mathrm{~nm} \times$ $75 \mathrm{~nm}$ ) of sample (b) $12 \mathrm{~h}$ later, recorded at constant-current image with $I_{\mathrm{t}}=0.26 \mathrm{nA}$ and $V_{\text {bias }}=-0.6 \mathrm{~V}$. The inset shows a zoom $(5 \mathrm{~nm} \times 3.5 \mathrm{~nm})$ of an island of ordered molecules recorded with $I_{\mathrm{t}}=0.03 \mathrm{nA}$ and $V_{\text {bias }}=0.8 \mathrm{~V}$.

inspecting the different surface terraces in the images, it can be observed that the striped domains display three different orientations rotated by $60^{\circ}$, according to the substrate 3 -fold symmetry (Figure 2a, regions labeled as A, B, and C). A zoom of the STM image (Figure 2c) shows that the rows are formed by double linear molecular chains. The rounded features that form each linear chain present a size of about $0.5 \mathrm{~nm}$, and therefore they are assigned to single $p$-AP molecules. The blue rectangle indicates the unit cell of the molecular domain. The inset in Figure $2 \mathrm{c}$ shows the detail of two molecular chains, where four molecules are observed. On the other hand, in contrast to the $p-\mathrm{AP} / \mathrm{Cu}(110)$ system, when acquiring STM images at different voltage polarities, differences between occupied and unoccupied states are observed (see Figures $2 \mathrm{c}$ 

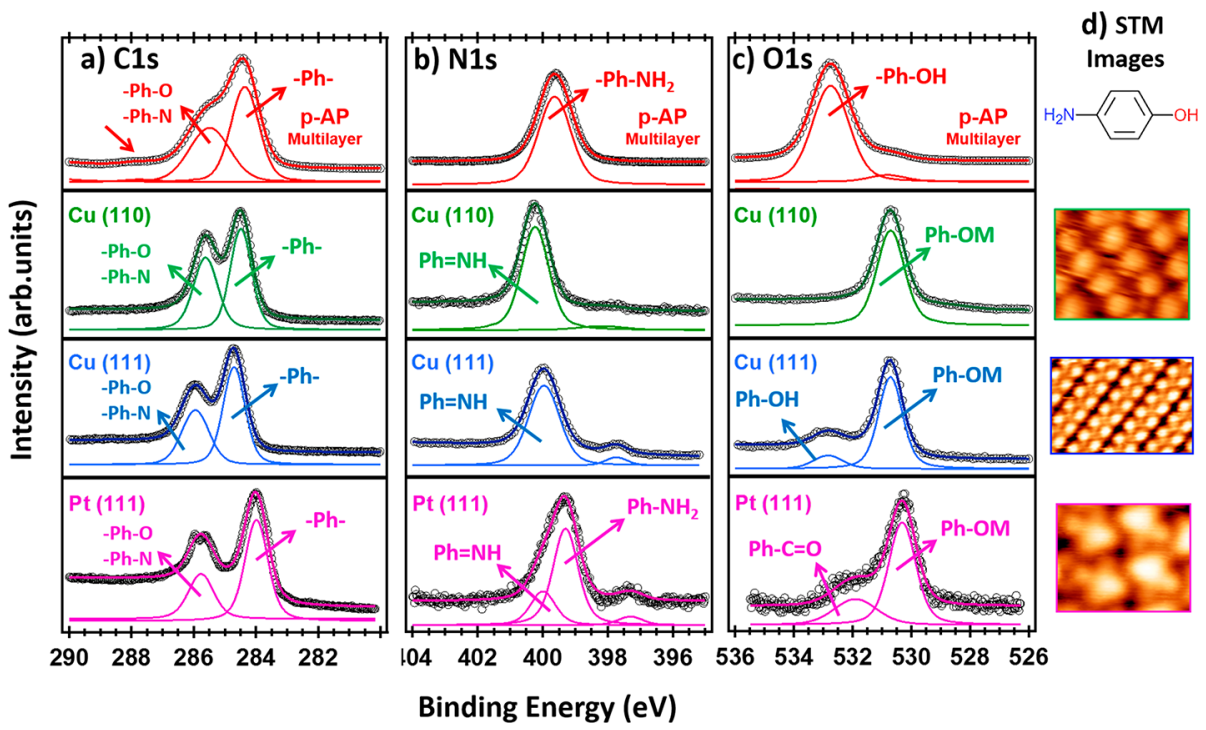

Figure 4. $(\mathrm{a}-\mathrm{c}) \mathrm{C} 1 \mathrm{~s}, \mathrm{~N} 1 \mathrm{~s}$, and $\mathrm{O} 1 \mathrm{~s}$ XPS spectra for a multilayer coverage of $p$-AP molecules (red curve), for $p$-AP/Cu(110) (green curve), for $p$ $\mathrm{AP} / \mathrm{Cu}(111)$ (blue curve), and for $p-\mathrm{AP} / \mathrm{Pt}(111)$ (pink curve), where the contribution of the different chemical species is indicated. (d) $p$-AP chemical structure and STM images corresponding to the different self-assembled monolayers of $p$-AP on the different single crystal surfaces.

and $2 \mathrm{~d}$, respectively). Both images represented in Figures $2 \mathrm{c}$ and $2 \mathrm{~d}$ were recorded on the same region but using different polarity. As a reference, the purple arrows indicate the same point at the sample surface for both images. The inset of Figure $2 \mathrm{~d}$ exhibits a detail of the molecular chains recorded at positive bias, which differs from that recorded at negative bias (inset of Figure 2c). As it can be observed, additional smaller protrusions, bright and rounded, appear along the row direction in between the linear chains at positive bias (empty states). Size and periodicity considerations indicate that these protrusions do not correspond to $p$-AP molecules; rather, they can be associated with $\mathrm{Cu}$ adatoms either native or promoted slightly out of the substrate plane. ${ }^{27,28}$ The latter case is the most probable according to the theoretical calculations (shown below).

The LEED pattern of the $p-\mathrm{AP} / \mathrm{Cu}(111)$ system is shown in Figure $2 \mathrm{~b}$, together with its simulation in the inset, where the different colors correspond to the three different rotational domains of the linear rows, as observed by STM. The analysis of the pattern indicates that the structure follows a $[(-3,0)$, $(-4,-8)]$ symmetry with respect to the $\mathrm{Cu}(111)$ surface, which results in a rectangular cell of dimensions $0.8 \mathrm{~nm} \times 1.8$ $\mathrm{nm}$ (see red rectangle in Figure $2 \mathrm{~b}$ ). This unit cell in the reciprocal space is in agreement with the blue unit cell inferred, for the real space, from the STM images (Figures $2 c$ and $2 \mathrm{~d}$ ).

Figure 3a shows a STM image of a high coverage deposition of $p$-AP molecules on $\mathrm{Pt}(111)$ at $\mathrm{RT}$. In this case, the $p$-AP molecules appear on the surface forming ordered domains in small areas, where the short-range order consists of linearly arranged $p$-AP molecules. In contrast to the adsorption on copper surfaces, where $p$-AP molecules appear as bright rounded protrusions at STM (see Figures $1 \mathrm{~b}$ and $2 \mathrm{c}$ ), on $\mathrm{Pt}(111)$ they display a rhomboidal shape of $0.9 \mathrm{~nm} \times 0.5 \mathrm{~nm}$ for the long and short axis, respectively (see bottom left inset of Figure 3a). Thus, the long axis size is larger than that of a free-standing $p$-AP molecule. This difference can be due to an electronic effect as a consequence of the adsorption of the $p$ AP molecule on the surface. ${ }^{16}$ However, it is also possible that the small round protrusion observed at the molecule end (see the inset of Figure 3a) corresponds to a Pt atom slightly protruding off the surface and coordinated to the oxygen atom.

For molecular coverage lower than that of Figure 3a, molecules are distributed randomly in small chains (see Figure $3 b$ ). The difference of the observed structures for high and intermediate coverage may be related to the higher molecular mobility in the latter due to free areas. However, if the system is allowed to evolve overnight at RT (see Figure 3c), islands of linear $p$-AP molecular chains predominantly oriented following the main crystallographic directions of the surface are observed. Over time, $p$-AP molecules change not only their self-assembly but also their STM topographic shape at RT. Initially, for intermediate molecular coverage, $p$-AP molecules appear as bright rounded protrusions as it can be observed in the inset of Figure $3 b$, where the yellow circle includes several $p$-AP molecules. However, with time the $p$-AP shape evolves to a rhomboidal appearance, as it can be observed in the inset of Figure $3 c$, where the white rectangle represents the region corresponding to one $p$-AP molecule, whose internal structure is formed by four bright rounded protrusions at the vertex of the rhombus. The ends of the major axis are assigned to the functional groups (the alcohol and amino group) of the benzene ring in para positions while the minor axis corresponds to the benzene ring itself. This change, from rounded to rhomboidal shape, could be attributed to a chemical transformation of the $p$-AP molecule induced by the surface or to a different adsorption configuration. ${ }^{16}$ Finally, no differences were observed in the STM images of the molecules for occupied or unoccupied states.

The STM and LEED results obtained by evaporating $p$-AP on the different surfaces indicate that for the two $\mathrm{Cu}$ faces different molecular arrangements were originated. These different orderings emerge from the balance between molecule-molecule and substrate-molecule interactions for the different surface symmetries. It must be considered that for the same material, copper in this case, the (111) surface symmetry, where all atoms are at the same surface plane, is less reactive than the (110), where linear rows protruding from the surface plane are present. For this reason, for the $\mathrm{Cu}(111)$ substrate a weaker interaction between the molecules and the 
surface could be expected with respect to $\mathrm{Cu}(110)$. Because of this weaker interaction, the diffusion of $p$-AP on $\mathrm{Cu}(111)$ is higher than on $\mathrm{Cu}(110)$, favoring the formation of longer ordered domains, which can even be enhanced with time or annealing. On the other hand, when depositing $p$-AP molecules on platinum, only short-range order is observed initially. It has to be taken into account that platinum has a greater chemical reactivity than copper toward dehydrogenation reactions. ${ }^{11}$ This behavior is related to the electrons of the valence band that are responsible for defining the molecule-substrate interaction, making it stronger for the Pt case. Therefore, the observation of a molecular self-assembly with lower degree of order than those of $\mathrm{Cu}$ surfaces, even in the case of presenting the same surface symmetry, was expected.

XPS and NEXAFS Analysis. The different chemical transformations of $p$-AP produced as a consequence of its adsorption at RT on these different surfaces were followed by in situ high-resolution XPS and NEXAFS. Figures $4 a-c$ show the high-resolution XPS spectra recorded at the $\mathrm{O} 1 \mathrm{~s}, \mathrm{~N} 1 \mathrm{~s}$, and $C 1$ s core levels for the different samples while Figure $4 \mathrm{~d}$ exhibits the $p$-AP chemical structure as well as the STM images for the different $p$-AP self-assembled monolayers on the three substrates. With regard to the XPS C 1s core levels (Figure $4 a)$, two contributions are observed for all the samples. In a multilayer system (red curve), similar to the pristine molecule, the main peak centered at $284.4 \mathrm{eV}$ can be assigned to the aromatic carbon ring $(\mathrm{Ph})$. The less intense emission, at 285.7 $\mathrm{eV}$, is associated with the carbon atoms bonded to the alcohol and the amine groups $\left(\mathrm{Ph}-\mathrm{OH}\right.$ and $\left.\mathrm{Ph}-\mathrm{NH}_{2}\right)$, the former expected at $\sim 0.5 \mathrm{eV}$ larger binding energy than the amino carbon. $^{22,29,30}$ A third small component, located around 287.5 $\mathrm{eV}$, can be attributed to a shakeup satellite (marked with a red arrow). ${ }^{31}$ For the $p-\mathrm{AP} /$ substrates spectra, the relative energy shift between the two main contributions varies slightly due to the different interaction of the molecules with each surface. In the specific case of the $p-\mathrm{AP} / \mathrm{Pt}(111)$ system, the energy difference is significantly increased due to a major shift to lower binding energy of the aromatic carbon contribution. This large shift suggests a significant charge transfer from the substrate to the molecular ring backbone, as will be confirmed by NEXAFS and in agreement with the different intramolecular contrast revealed by STM as compared to the $\mathrm{Cu}$ substrates. The overall larger interaction of $p$-AP with Pt rather than with $\mathrm{Cu}$ is also witnessed by the splitting of the $\mathrm{C} 1 \mathrm{~s}$ peak of the carbon atoms bonded to the hydroxyl and amine terminations. However, because of the proximity of the two emissions, we have fitted these spectral features with a single component including both emissions.

The XPS N 1s core-level spectra are shown in Figure 4b. For the pristine $p$-AP molecule, a single contribution, located at $399.6 \mathrm{eV}$, assigned to the amine group $\left(-\mathrm{Ph}-\mathrm{NH}_{2}\right)$ is observed (red curve). ${ }^{32-34}$ In the case of $p-\mathrm{AP} / \mathrm{Cu}(110)$ (green curve), a signal at $400.2 \mathrm{eV}$ is detected. Upon comparison with pristine $p$-AP, the signal has shifted toward higher binding energies $(+0.6 \mathrm{eV})$. This change can be ascribed to the partial dehydrogenation of the amine group since the signal corresponds to the $-\mathrm{NH}$ group. ${ }^{35}$ In the case of $p-\mathrm{AP} / \mathrm{Cu}(111)$ (blue curve), a main contribution at 399.97 $\mathrm{eV}$ is observed. Similarly to the $\mathrm{Cu}(110)$ case, this emission would correspond to the partial dehydrogenation of the amine group $(-\mathrm{Ph}=\mathrm{NH})$. This result indicates that the absorption of $p$-AP on the copper surfaces leads to the chemical transformation of the amine group. The $p-\mathrm{AP} / \mathrm{Pt}(111)$ spectrum (pink curve) shows a broad peak formed by two contributions, located at 399.35 and $399.98 \mathrm{eV}$. The higher intensity component corresponds to the amine group, and the lower one is caused by the oxidation of the amine group due to a dehydrogenation process $\left(-\mathrm{NH}_{2} \rightarrow=\mathrm{NH}\right) .{ }^{35}$ Finally, it has been observed in all the $p$-AP/substrates systems a small signal around $397.5 \mathrm{eV}$, which is attributed to some kind of contamination.

By analyzing the XPS $O$ 1s core-level spectrum of the pristine $p$-AP molecule, we observed two contributions: a main signal centered at $532.8 \mathrm{eV}$ and a minor signal at around 530.7 $\mathrm{eV}$ (see red curve in Figure 4c). The former emission is assigned to the alcohol group of the pristine molecule $(-\mathrm{Ph}-$ $\mathrm{OH}),{ }^{36}$ while the latter one is ascribed to the first layer of molecules in contact with the surface, where the molecules are dehydrogenated (phenoxy structure, $-\mathrm{Ph}-\mathrm{O}-$ ) and stabilized by the surface. ${ }^{37,38}$ When the molecule is on the surface, the same chemical transformation, dehydrogenation of the alcohol group, prevails. In the case of $p-\mathrm{AP} / \mathrm{Cu}(110)$ (green curve), we observe a single contribution at $530.7 \mathrm{eV}$, which indicates that this chemical transformation, from the alcohol group to phenoxy structure, is complete. In the case of $p-\mathrm{AP} / \mathrm{Cu}(111)$ (blue curve), we observe two contributions: one centered at $530.7 \mathrm{eV}$ and another, with lower intensity, at $532.8 \mathrm{eV}$. By comparison with the pristine $p$-AP system, we can ascribe these emissions to a phenoxy and an alcohol structure, ${ }^{36-38}$ respectively, suggesting an incomplete chemical transformation from alcohol to phenoxy. As mentioned above, this surface is less reactive than the $\mathrm{Cu}(110)$, and the dehydrogenation reaction is incomplete. As we have already determined by STM, this issue could be solved by leaving the system ripening longer or by an energy supply, for example, by increasing the substrate temperature. Finally, in the case of the $p-\mathrm{AP} / \mathrm{Pt}(111)$ system (pink curve), we observed a main signal centered at $530.3 \mathrm{eV}$ and a lower intensity signal at $531.9 \mathrm{eV}$. The main contribution, which again is due to the phenoxy structure, presents a shift toward lower binding energy as compared with the other systems, which we attribute to a charge transfer from the platinum surface. The second contribution at $531.9 \mathrm{eV}$ is associated with a ketone group originated by the oxidation of the alcohol $(\mathrm{C}-\mathrm{OH} \rightarrow \mathrm{C}=\mathrm{O}) .{ }^{39}$ The results for $p-\mathrm{AP}$ on $\mathrm{Pt}$ indicate that most of the molecules are dehydrogenated and stabilized by the surface, while a minor contribution of the species appears in a ketone form.

To get more insights into the processes, we also performed NEXAFS at the C K-edge ionization threshold for the three systems. The spectra measured in $\mathrm{s}$ and $\mathrm{p}$ polarization are shown in Figure 5.

The NEXAFS spectra of the three systems can be roughly divided in two regions: $\pi^{*}$ - and $\sigma^{*}$-symmetry regions. In the $p$ $\mathrm{AP} / \mathrm{Cu}$ systems, three transitions are observed at the $\pi^{*}$ symmetry region. The most intense signal at $\sim 285 \mathrm{eV}$ is associated with a transition to the $\pi^{*}$ LUMO of the aromatic carbons $\left(\mathrm{C}_{\text {ring }}\right)$. The second resonance at $\sim 287 \mathrm{eV}$ is associated with the transition to the $\pi^{*}$ orbital of both $\mathrm{C}-\mathrm{N}$ and C-O molecular groups. ${ }^{29,40}$ The third resonance at $\sim 290$ $\mathrm{eV}$ has been attributed to higher energy orbitals mostly localized on the carbon ring. ${ }^{40}$ The NEXAFS measured on $p$ $\mathrm{AP} / \mathrm{Pt}(111)$ deviates significantly from those on $\mathrm{Cu}$. All the main resonances are strongly quenched and shifted to lower energy due to the charge transfer from the substrate to the unoccupied molecular orbitals, in agreement with the large core level shift observed in the C 1s XPS. The corresponding 


\section{K-edge}

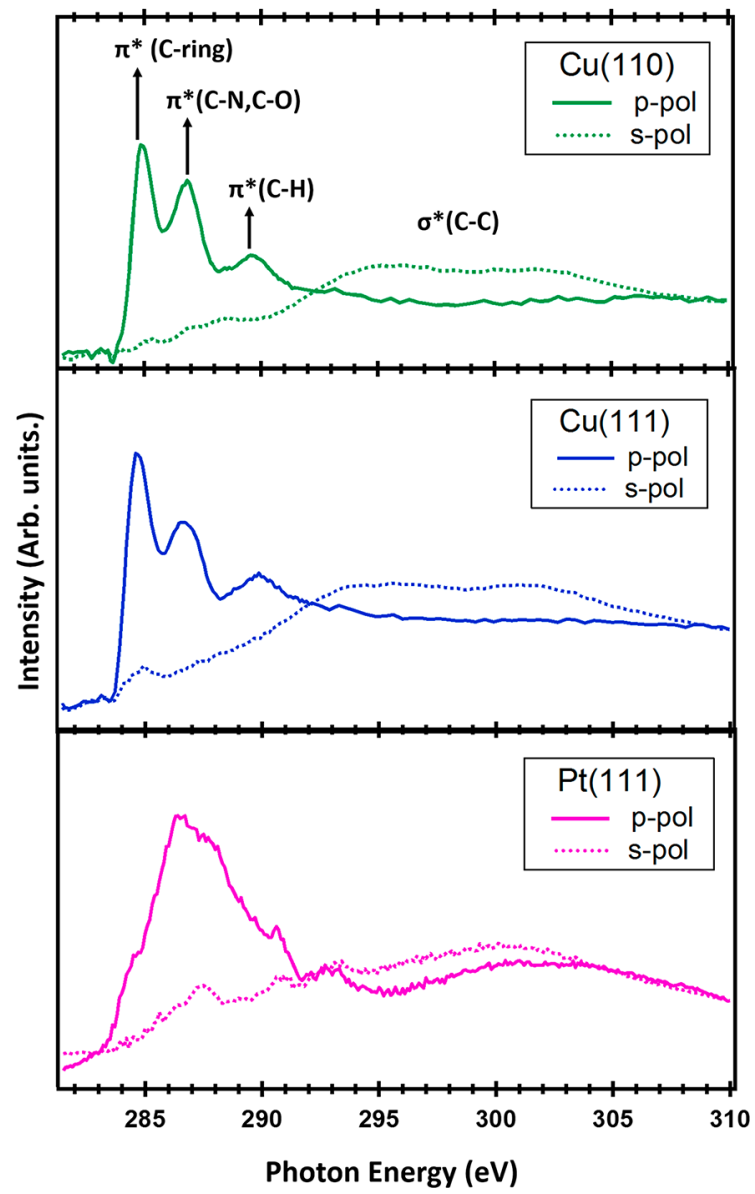

Figure 5. NEXAFS C K-edge spectra taken for $\mathrm{p}$ and $\mathrm{s}$ polarizations (solid and dotted curves, respectively) after evaporation of $p$-AP molecules on $\mathrm{Cu}(110)$ (green curves), $\mathrm{Cu}(111)$ (blue curves), and $\mathrm{Pt}(111)$ (pink curves).

large rehybridization of the molecular orbitals does not allow to disentangle the contribution from the different carbon components (apart from the weak shoulder at $\sim 284.5 \mathrm{eV}$, likely associated with the partially filled, hence quenched and shifted, ring atoms). However, the overall $\pi^{*}$ symmetry of the resonances below the ionization threshold is preserved.

We can estimate quantitatively the average molecular orientation with respect to the surface from the intensity ratio of the NEXAFS resonances measured in $s$ and $p$ polarization. Stöhr equations have been used to estimate the angle of the $p$-AP molecules on the 2 -fold $\mathrm{Cu}(110)$ and the 3fold $\mathrm{Cu}(111)$ and $\mathrm{Pt}(111)$ surface symmetries. ${ }^{41}$ Taking into consideration the benzene ring configuration, which presents its $\mathrm{p}_{z}$ orbitals perpendicular to the plane of the ring, we have measured the area of the $\pi^{*}\left(\mathrm{C}_{\text {ring }}\right)$ symmetry signal for $\mathrm{p}$ and $\mathrm{s}$ polarizations of the $\mathrm{C}$ K-edge spectrum. In the case of the $p$ $\mathrm{AP} / \mathrm{Pt}(111)$ system, we rather considered the area of the $\pi^{*}$ region as a whole. This analysis reveals average angles of the molecules with respect to the surface of $5.6^{\circ}, 21.0^{\circ}$, and $13.0^{\circ}$ for $p-\mathrm{AP} / \mathrm{Cu}(110), p-\mathrm{AP} / \mathrm{Cu}(111)$, and $p-\mathrm{AP} / \mathrm{Pt}(111)$, respectively. In the case of the system with the larger angle value, that of the $\mathrm{Cu}(111)$ substrate, there is a nonvanishing $\pi^{*}$ $\left(\mathrm{C}_{\text {ring }}\right)$ resonance at $\mathrm{s}$ polarization (Figure 5$)$, which further indicates that the molecules are tilted with respect to the surface. In fact, similar angle values have been previously reported for the case of benzene on $\mathrm{Cu}(111)$ and on $\mathrm{Ag}(110)$, which were attributed to a small fraction of molecules bonded with a tilted orientation at defect sites. ${ }^{42,43}$ In the case of the $p$ $\mathrm{AP} / \mathrm{Cu}(111)$ system, the tilt angle could be overestimated because the residual NEXAFS intensity of $\pi^{*}$ resonances in $\mathrm{s}$ polarization might be associated with a distortion of the rehybridized molecular orbitals.

All these results evidence that the chemical structure of $p$-AP is different depending on the catalytic properties of each surface. In the case of $\mathrm{Cu}(110)$ and $\mathrm{Cu}(111)$ systems, $p$-AP molecules undergo the RT spontaneous dehydrogenation of the alcohol group forming a phenoxy species that is stabilized through the metal surface $(\mathrm{Ph}-\mathrm{OM})$. In the case of $\mathrm{Cu}(110)$, this chemical conversion is complete, while on $\mathrm{Cu}(111)$ the dehydrogenation can be completed by time or by temperature. In addition, the amine group undergoes a partial dehydrogenation $(\mathrm{Ph}=\mathrm{NH})$. In the case of $\mathrm{Pt}(111)$, the dehydrogenation of the alcohol group takes place, and additionally, a minority chemical transformation leads to the oxidation reaction from the alcohol to the ketone group $(\mathrm{Ph}-\mathrm{OH} \rightarrow \mathrm{Ph}=\mathrm{O})$. Finally, in this surface not all $p$-AP molecules undergo a dehydrogenation reaction of amine group $(\mathrm{Ph}=\mathrm{NH})$. In conclusion, the results suggest a more reactive behavior of the (110) symmetry surface and a more intense catalytic activity of $\mathrm{Pt}$ with respect to $\mathrm{Cu}$, which induce different chemical transformations of the p-AP adsorbed molecules.

DFT Analysis. Finally, and to get some insights into the specific structural and electronic properties of the different adsorbed configurations, we have performed a battery of density functional theory (DFT)-based calculations for the $p$ $\mathrm{AP} / \mathrm{Cu}(110)$ and $p-\mathrm{AP} / \mathrm{Cu}(111)$ interfaces similar to that performed previously for the $p-\mathrm{AP} / \mathrm{Pt}(111)$ case. ${ }^{16}$ We have started the theoretical protocol by elucidating, for an isolated p-AP molecule (with $-\mathrm{O}$ and $-\mathrm{NH}$ terminating groups according to the experimental evidence) on both $\mathrm{Cu}(111)$ and $\mathrm{Cu}(110)$ surfaces, the preferential (i) on-surface adsorption site (referred to the center of the molecular C-ring) and (ii) the on-surface molecular orientation with respect to the highsymmetry surface directions. Figure 6a shows all the inequivalent on-surface adsorption sites and molecular orientations tested for $p-\mathrm{AP} / \mathrm{Cu}(111)$ and $p-\mathrm{AP} / \mathrm{Cu}(110)$, and Figure $6 \mathrm{~b}$ shows the two most stable computed interfacial adsorption configurations for both systems. Table 1 reports the computed total energies for all the inequivalent configurations according to Figure $6 \mathrm{a}$ and referred to the most stable structures.

According to the theoretical prediction, the most stable structures for an isolated $p$-AP molecule on $\mathrm{Cu}(111)$ and $\mathrm{Cu}(110)$ are those named $1 \mathrm{~B}$ and $3 \mathrm{BS}$, respectively. In the $p$ $\mathrm{AP} / \mathrm{Cu}(111) 1 \mathrm{~B}$ case the molecule is quite flat, and the center of its molecular C-ring lies on a "bridge" site with molecular orientation following the $[1 \overline{2} 1]$ direction, named orientation 1 . In this $1 \mathrm{~B}$ configuration the $\mathrm{O}$ atom links "on-top" a $\mathrm{Cu}$ atom, while the $\mathrm{NH}$ lies on a "bridge" position. In the $p-\mathrm{AP} / \mathrm{Cu}(111)$ $2 \mathrm{H}$ configuration the molecule is also quite flat, and the center of its molecular C-ring lies on a "hollow" site with molecular orientation following the $[1 \overline{1} 0]$ direction, named orientation 2 . In this $2 \mathrm{H}$ configuration the $\mathrm{O}$ atom links on a $\mathrm{Cu}-\mathrm{Cu}$ "bridge", and the NH lies again on a "bridge" position. Thus, the preferential molecular adsorption site for $\mathrm{Cu}(111)$ is with the center of the C-ring on a "bridge" along 1 with a lower energy by $+0.22 \mathrm{eV}$ with respect to the $2 \mathrm{H}$ case. Nonetheless, for the case of the $p-\mathrm{AP} / \mathrm{Cu}(110)$ interface, there is a clear 
a)
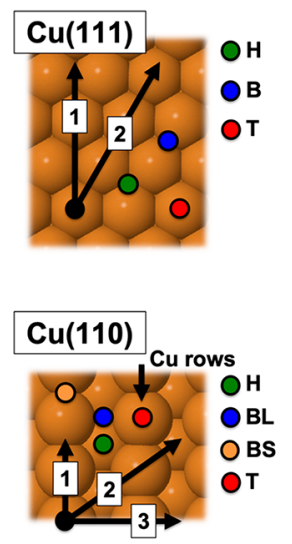

b)

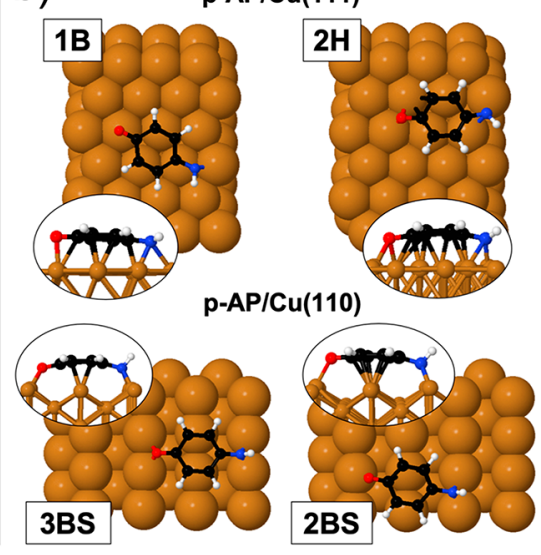

Figure 6. (a) Inequivalent on-surface adsorption sites (referred to the center of the molecular C-ring) and molecular orientations for the $\mathrm{Cu}(111)$ (top): "hollow" (H), "bridge" (B), and "top" (T) sites and orientations 1 (along the [121] direction) and 2 (along the [110] direction), and for $\mathrm{Cu}(110)$ (bottom): (top): "hollow" (H), "long bridge" (BL), "short bridge" (BS), and "top" (T) sites, and orientations 1 (along the $[\overline{1} 10]$ direction), 2 (along the $[\overline{111}]$ direction), and 3 (along the [001] direction). (b) Top and side pictorial views of the two most stable computed interfacial adsorption configurations for $p-\mathrm{AP} / \mathrm{Cu}(111)$ (top) and $p-\mathrm{AP} / \mathrm{Cu}(110)$ (bottom). White, gray, blue, red, and tan spheres correspond to $\mathrm{H}, \mathrm{C}, \mathrm{N}$, $\mathrm{O}$, and $\mathrm{Cu}$ atoms, respectively.

preference of the molecule to locate the center of the C-ring on a "short bridge" site, being oriented along the [001] direction, named 3, corresponding to the 3BS structure. The following more stable structure on $\mathrm{Cu}(110)$ would be the $2 \mathrm{BS}$ slightly oriented along the $[\overline{1} 11]$ direction, named 2 , less favorable in energy by $+0.23 \mathrm{eV}$.

Taking into account the previous theoretical predictions and the above-mentioned experimental evidence (STM, LEED, XPS, and NEXAFS), we have constructed several starting-point models for both $p-\mathrm{AP} / \mathrm{Cu}(111)$ and $p-\mathrm{AP} / \mathrm{Cu}(110)$ interfacial systems.

For the case of the $p-\mathrm{AP} / \mathrm{Cu}(110)$ interface, experimental LEED images point to a molecular on-surface arrangement following a $4 \times 4$ unit cell, with three molecules per unit cell according to the experimental STM images. On this basis, we have constructed different starting-point models to be fully DFT optimized (a total number of 12 configurations). Among all the resulting 12 DFT fully relaxed configurations we find five of them lying within a tiny total energy range of $0.18 \mathrm{eV} /$ molecule, in particular, with the closest-in-energy interfacial configuration to the ground state yielding a total energy of 0.09

$\mathrm{eV} /$ molecule with respect to the most stable configuration. In a step beyond we have simulated the Keldish-Green STM images of these low-lying in total energy configurations within the same experimental conditions adopted (constant-current regime with $I_{\mathrm{t}}=0.1 \mathrm{nA}$ and $\left.V_{\text {bias }}=+1.5 \mathrm{~V}\right)$. The theoretical prediction of several interfacial geometries lying in such a short total energy range may indicate the simultaneous coexistence of some of them in the experiment. This observation could explain why is the closest-in-energy interfacial configuration to the theoretically more stable structure (by $0.09 \mathrm{eV} /$ molecule) that accurately mimics the experimental STM image, instead of the ground state, whose computed theoretical STM image fits significantly worse than the previous one (see below).

Figures $7 \mathrm{a}$ and $7 \mathrm{~b}$ show the top and side views of the bestfitting structure for the $p-\mathrm{AP} / \mathrm{Cu}(110)$ interface according to
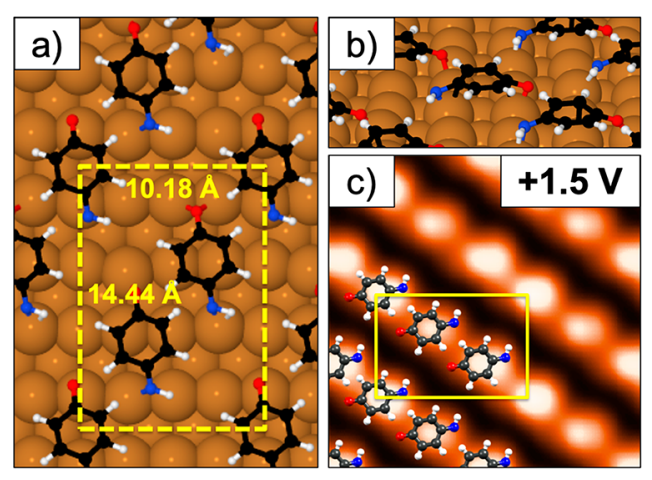

Figure 7. (a) Top view and (b) side view of the DFT optimized model proposed for the $p-\mathrm{AP} / \mathrm{Cu}(110)$ interface. White, black, blue, red, and tan spheres correspond to $\mathrm{H}, \mathrm{C}, \mathrm{N}, \mathrm{O}$, and $\mathrm{Cu}$ atoms, respectively. The unit cell used in the calculations is indicated by a yellow dashed-line rectangle. (c) Simulated Keldish-Green STM image at constant-current regime $\left(I_{\mathrm{t}}=0.1 \mathrm{nA}\right.$ and $\left.V_{\text {bias }}=+1.5 \mathrm{~V}\right)$ for the configuration of (a) and (b). For a comprehensive visualization the molecular adlayer is shown superimposed on the STM image.

the STM image, which is depicted in Figure 7c. As can be observed, two of the three molecules in the unit cell have the center of the molecular C-ring lying on a "short bridge" site: coinciding with the most favorable case found for an isolated $p$ AP molecule on $\mathrm{Cu}(110)$. Besides, the most electronegative part of the molecule, the terminating dehydrogenated $\mathrm{O}$, tends to connect with the metal via "top" and "bridge" sites, also agreeing with the case of an isolated $p$-AP molecule on $\mathrm{Cu}(110)$. The molecules lie on the surface practically flat (as in the isolated case), exhibiting a very slight tilt of around $2^{\circ}$ that permits each molecule maximizing the interaction with the substrate. As we can appreciate in Figure $7 c$, each protrusion

Table 1. Computed Total Energies (in eV) for the Inequivalent $p-\mathrm{AP} / \mathrm{Cu}(111)$ and $p-\mathrm{AP} / \mathrm{Cu}(110)$ Configurations According to Figure 6a, Referred to the Most Stable Ground-State Structures (G-S ${ }^{a}$

\begin{tabular}{ccccc}
\hline & 1B & 2H & 2B & 1T, 1H, 2T \\
\hline p-AP/Cu(111) & $\mathbf{0 . 0}(\mathbf{G}-\mathbf{S})$ & $+0.22 \mathrm{eV}$ & $+0.32 \mathrm{eV}$ & $>+0.45 \mathrm{eV}$ \\
& $\mathbf{3 B S}$ & $\mathbf{2 B S}$ & $\mathbf{2 T}$ & $\mathbf{1 H}, \mathbf{1 B S}, \mathbf{1 B L}, \mathbf{1 T}, \mathbf{2 H}, \mathbf{2 B L}, \mathbf{3 H}, \mathbf{3 B L}, \mathbf{3 T}$ \\
$\mathrm{p}-\mathrm{AP} / \mathrm{Cu}(110)$ & $\mathbf{0 . 0}(\mathbf{G}-\mathbf{S})$ & $+0.23 \mathrm{eV}$ & $+0.26 \mathrm{eV}$ & $>+0.64 \mathrm{eV}$ \\
\hline
\end{tabular}

${ }^{a}$ Total energies with respect to the G-S structures are explicitly reported for the three most stable configurations in each case. The total energies of the rest of the cases are indicated by means of a lower bound. 


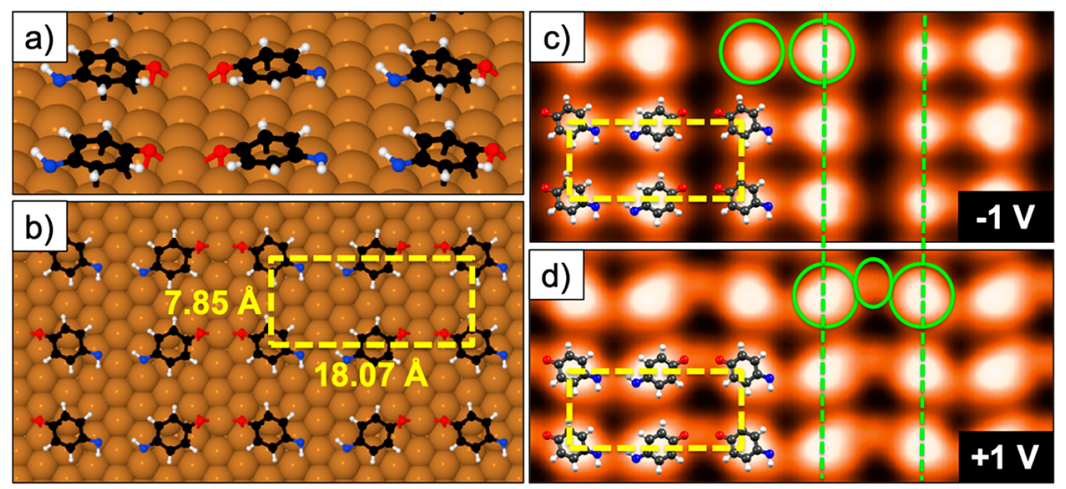

Figure 8. (a) Top and (b) side views of the most stable DFT optimized model for the $p$ - $\mathrm{AP} / \mathrm{Cu}(111)$ interface. White, dark gray, blue, red, and tan spheres correspond to $\mathrm{H}, \mathrm{C}, \mathrm{N}, \mathrm{O}$, and $\mathrm{Cu}$ atoms, respectively. The unit cell used in the calculations is indicated by a yellow dashed-line rectangle. Simulated Keldish-Green STM images at constant-current regime at $I_{\mathrm{t}}=0.1 \mathrm{nA}$ and $V_{\text {bias }}=-1 \mathrm{~V}(\mathrm{c})$ and $+1 \mathrm{~V}(\mathrm{~d})$ for the most stable configuration. For a comprehensive visualization, the molecular adlayer is shown superimposed on the STM images.

corresponds to individual molecules. Thus, we have chosen this one as best candidate because (a) it is the most stable configuration yielding a very similar STM image that the experiment and (b) the tilt angle of the molecule on the surface perfectly agrees with the NEXAFS experiment (see below). Nonetheless, we cannot close the door to conjecture that a bunch of different similar $(4 \times 4)-\mathrm{AP} / \mathrm{Cu}(110)$ configurations yielding similar experimental STM images could be coexisting on the surface by effect of the thermal bath at RT conditions. According to our DFT calculations on all calculated structures, the $\mathrm{Cu}$ atoms beneath the oxygen from the molecule experience an out-of-plane displacement of about $0.3 \AA$.

For the case of the $p-\mathrm{AP} / \mathrm{Cu}(111)$ interface, experimental LEED images indicate that the structure follows a $[(-3,0)$, $(-4,-8)]$ symmetry with respect to the $\mathrm{Cu}(111)$ surface, with two $p$-AP molecules per unit cell according to the experimental STM images. On the basis of this experimental evidence, together with the theoretical prediction for the adsorption of an isolated $p$-AP molecule on $\mathrm{Cu}(111)$ (see Figure 6), we have constructed several starting-point interfacial structures, varying again the on-surface adsorption site and molecular orientation, to be fully relaxed by DFT. Figure 8 shows the most stable configuration obtained from the simulations among all the initial structures tested. Figures $8 \mathrm{a}$ and $8 \mathrm{~b}$ show pictorial top and side views of the ground-state configuration obtained for $p-\mathrm{AP} / \mathrm{Cu}(111)$, where the molecules bind to the substrate though the terminal $\mathrm{O}$ atom and form an angle of around $22^{\circ}$ with respect to orientation 1 in $\mathrm{Cu}(111$ ) (see Figure 6), in such a way that along this orientation 1 are specular neighbors with respect to orientation 2, except for the different orientations of the $-\mathrm{NH}$ groups in adjacent molecules. This on-surface orientation may be due to several factors: (i) to the preference of the molecules of locating opposite to each other to minimize the on-surface molecular dipole moment, (ii) they maximize the interaction with the surface of activated $\mathrm{C}$ atoms of the C-ring, or (iii) this orientation seems to favor an efficient stabilization through a dipolar interaction between the adjacent terminal $-\mathrm{NH}$ groups connecting $\mathrm{NH}-\mathrm{NH}$, according to their alternating orientation.

Figures $8 \mathrm{c}$ and $8 \mathrm{~d}$ show the computed Keldish-Green STM images for the G-S configuration under constant-current conditions with $I_{\mathrm{t}}=0.1 \mathrm{nA}$ for $V_{\text {bias }}=-1$ and $+1 \mathrm{~V}$ (just like in Figure 2). As we can observe, the comparison between the experimental and theoretical images is good. At $V_{\text {bias }}=-1$
$\mathrm{V}$ we observe circular protrusions, each of them associated with an individual molecule, with a dimer region between the opposing $\mathrm{O}$ atoms, being the protrusions closest where the $-\mathrm{NH}$ groups connect. Interestingly, it is possible to observe, just like in the experimental image, protrusions of alternating intensity along direction 1 , which is related to the different onsurface sites of the alternating molecules. Nonetheless, for $V_{\text {bias }}$ $=+1 \mathrm{~V}$ the contrast of the image slightly switches, the protrusions enlarge along direction 1 , and this enlargement induces a dimer region than for $-1 \mathrm{~V}$ between the $-\mathrm{NH}$ groups, with a new protrusion appearing between the opposing $\mathrm{O}$ atoms. In the theoretical image this third protrusion is only slightly suggested and may be due to a charge depletion in the substrate that moves toward the molecules, which is reflected in the tunneling of unoccupied states. In the experimental image at $V_{\text {bias }}=+1 \mathrm{~V}$ the emerging third protrusion is much more clear and defined and could be due to either a $\mathrm{Cu}$ adatom or a slight out-of-plane promotion of a $\mathrm{Cu}$ atom of the substrate, both by effect of the temperature. Unfortunately, this effect is not so clearly observable in the calculations, which does not account for the effect of the temperature and hinders such a mass promotion in the substrate. Nonetheless, the $\mathrm{Cu}$ atom of the substrate just below the two adjacent $\mathrm{O}$ molecular atoms shows a slight out-of-plane buckling of around $0.2 \AA$, which reinforces this conjecture.

Finally, the previous calculations allow obtaining the average angle of the $p$-AP molecule with respect to both $\mathrm{Cu}$ substrates. Therefore, for $p-\mathrm{AP} / \mathrm{Cu}(111)$ a tilt angle of around $16^{\circ}$ is inferred, which points in the line of the angle obtained when using the NEXAFS data, $21 \pm 5^{\circ}$. On the other hand, for $p$ $\mathrm{AP} / \mathrm{Cu}(110)$ the average tilt angle obtained from the DFT calculations is around $2^{\circ}$, which although it is smaller than that obtained by NEXAFS is within its error range, $5.6 \pm 5^{\circ}$. The accuracy of the theoretical formalism determining distances can be assumed to be better than $1 \%$.

\section{CONCLUSIONS}

In this work, the adsorption of $p$-aminophenol molecules on different surfaces, $\mathrm{Cu}(110), \mathrm{Cu}(111)$, and $\mathrm{Pt}(111)$, has been investigated. The combination of STM, LEED, XPS, and NEXAFS together with theoretical calculations allows monitoring the influence of both the nature and symmetry of the surface on the adsorption processes. For the less reactive metal (copper), the experiments reveal a linear long-order assembly and a short-order arrangement of $p$-AP on the (111) 
and the (110) faces, respectively, due to the large diffusion that the molecules undergo on those surfaces. In both $\mathrm{Cu}$ surfaces, the experimental data show the spontaneous dehydrogenation of the alcohol group of the $p$-AP molecule to form a phenoxy species; however, this process is not totally complete in $\mathrm{Cu}(111)$, as expected since the (111) face is less reactive than the (110) face. The amine group in both surfaces partially dehydrogenates. STM and LEED experiments on the highly reactive $\mathrm{Pt}(111)$ surface reveal a short-order molecular disposition due to the strong interaction between molecules and surface. However, the molecular layer arranges in a linear order with time. Additionally, it is observed that $p$-AP on $\mathrm{Pt}(111)$ undergoes mainly the dehydrogenation of the alcohol group to form the phenoxy species and to a lesser extent the oxidation reaction to form ketone. The amine group in the case of $\mathrm{Pt}(111)$ and similarly to the $\mathrm{Cu}$ surfaces is partially dehydrogenated. In summary, the present work evidences the crucial role of the surface properties on the adsorption mechanisms of molecules, determining the chemical and the structural behavior of the resulting molecular layer.

\section{AUTHOR INFORMATION}

\section{Corresponding Author}

María F. López - Institute of Material Science of Madrid (ICMM-CSIC), 28049 Madrid, Spain; 이이.org/00000001-7894-566X; Phone: +34913349081; Email: mflopez@ icmm.csic.es

\section{Authors}

Nerea Ruiz del Árbol - Institute of Material Science of Madrid (ICMM-CSIC), 28049 Madrid, Spain

Irene Palacio - Institute of Material Science of Madrid (ICMMCSIC), 28049 Madrid, Spain; ㅇ orcid.org/0000-0002-33454848

Carlos Sánchez-Sánchez - Institute of Material Science of Madrid (ICMM-CSIC), 28049 Madrid, Spain; 이이.org/ 0000-0001-8644-3766

Gonzalo Otero-Irurueta - Centre of Mechanical Technology and Automation (TEMA), University of Aveiro, 3810-193 Aveiro, Portugal

José I. Martínez - Institute of Material Science of Madrid (ICMM-CSIC), 28049 Madrid, Spain

Luis Rodríguez - Institute of Material Science of Madrid (ICMM-CSIC), 28049 Madrid, Spain

David Serrate - Instituto de Ciencia de Materiales de Aragón, CSIC-Universidad de Zaragoza, 50009 Zaragoza, Spain; (1) orcid.org/0000-0002-3260-9641

Albano Cossaro - Laboratorio TASC, CNR-IOM, I-34149 Trieste, Italy; Department of Chemical and Pharmaceutical Sciences, Università degli Studi di Trieste, 34127 Trieste, Italy; (1) orcid.org/0000-0002-8429-1727

Paolo Lacovig - Elettra-Sinctrotrone Trieste S.C.p.A., I-34149

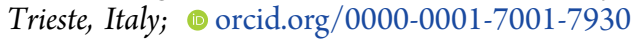

Silvano Lizzit - Elettra-Sinctrotrone Trieste S.C.p.A., I-34149 Trieste, Italy; ○orcid.org/0000-0003-1620-7228

Alberto Verdini - Laboratorio TASC, CNR-IOM, I-34149 Trieste, Italy; ○ orcid.org/0000-0001-8880-2080

Luca Floreano - Laboratorio TASC, CNR-IOM, I-34149 Trieste, Italy; 이이이.org/0000-0002-3654-3408

José A. Martín-Gago - Institute of Material Science of Madrid

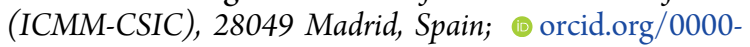
0003-2663-491X

Complete contact information is available at: https://pubs.acs.org/10.1021/acs.jpcc.0c06101

\section{Notes}

The authors declare no competing financial interest.

\section{ACKNOWLEDGMENTS}

This work was supported by the Spanish MINECO (Grant MAT2017-85089-C2-1-R) and the EU via the ERC-Synergy Program (Grant ERC-2013-SYG-610256 NANOCOSMOS). The authors thank "Comunidad de Madrid" for its support of the FotoArt-CM project (S2018/NMT-4367) through the Program of R\&D activities between research groups in Technologies 2018, cofinanced by European Structural Funds. N.R. acknowledges support from the FPI program of Spanish MINECO (BES-2015-072642). C.S.S. acknowledges MCIU for the "Ramón y Cajal" contract (RYC2018-024364-I). G.O.-I. thanks FCT for his contract (IF/01054/2015). The use of the infrastructure at the Advanced Microscopy Laboratory (LMA) is acknowledged.

\section{REFERENCES}

(1) Frontiers in Surface and Interface Science; Duke, C. B., Plummer, E. W., Eds.; North-Holland: Amsterdam, 2002.

(2) Lindner, R.; Kühnle, A. On-surface reactions. ChemPhysChem 2015, 16, 1582-1592.

(3) Clair, S.; De Oteyza, D. G. Controlling a Chemical Coupling Reaction on a Surface: Tools and Strategies for On-Surface Synthesis. Chem. Rev. 2019, 119, 4717-76.

(4) Sánchez-Sánchez, C.; Martínez, J. I.; Ruiz Del Arbol, N.; Ruffieux, P.; Fasel, R.; López, M. F.; de Andrés, P. L.; Martín-Gago, J. A. On-Surface Hydrogen-Induced Covalent Coupling of Polycyclic Aromatic Hydrocarbons via a Superhydrogenated Intermediate. J. Am. Chem. Soc. 2019, 141, 3550-3557.

(5) Krüger, J.; García, F.; Eisenhut, F.; Skidin, D.; Alonso, J. M.; Guitián, E.; Pérez, D.; Cuniberti, G.; Moresco, F.; Peña, D. Decacene: On-Surface Generation. Angew. Chem., Int. Ed. 2017, 56, 1194511948.

(6) Moreno, C.; Vilas-Varela, M.; Kretz, B.; Garcia-Lekue, A.; Costache, M. V.; Paradinas, M.; Panighel, M.; Ceballos, G.; Valenzuela, S. O.; Peña, D.; et al. Bottom-up synthesis of multifunctional nanoporous graphene. Science 2018, 360, 199-203.

(7) Otero, G.; Biddau, G.; Sánchez-Sánchez, C.; Caillard, R.; López, M. F.; Rogero, C.; Palomares, F. J.; Cabello, N.; Basanta, M. A.; Ortega, J.; et al. Fullerenes from aromatic precursors by surfacecatalysed cyclodehydrogenation. Nature 2008, 454, 865-868.

(8) Xing, L.; Peng, Z.; Li, W.; Wu, K. On Controllability and Applicability of Surface Molecular Self-Assemblies. Acc. Chem. Res. 2019, 52, 1048-1058.

(9) Goiri, E.; Borghetti, P.; El-Sayed, A.; Ortega, J. E.; De Oteyza, D. G. Multi-Component Organic Layers on Metal Substrates. Adv. Mater. 2016, 28, 1340-1368.

(10) Barth, J. V. Molecular Architectonic on Metal Surfaces. Annu. Rev. Phys. Chem. 2007, 58, 375-407.

(11) Méndez, J.; López, M. F.; Martín-Gago, J. A. On-surface synthesis of cyclic organic molecules. Chem. Soc. Rev. 2011, 40, 45784590.

(12) Mali, K. S.; De Feyter, S. Principles of molecular assemblies leading to molecular nanostructures. Philos. Trans. R. Soc., A 2013, 371, 20120304.

(13) Maurer, R. J.; Ruiz, V. G.; Camarillo-Cisneros, J.; Liu, W.; Ferri, N.; Reuter, K.; Tkatchenko, A. Adsorption structures and energetics of molecules on metal surfaces: Bridging experiment and theory. Prog. Surf. Sci. 2016, 91, 72-100.

(14) Palacio, I.; Pinardi, A. L.; Martínez, J. I.; Preobrajenski, A.; Cossaro, A.; Jancarik, A.; Stará, I.; Starý, I.; Méndez, J.; Martín-Gago, J. A.; et al. Spectroscopic characterization of the on-surface induced 
(cyclo)dehydrogenation of a N-heteroaromatic compound on noble metal surfaces. Phys. Chem. Chem. Phys. 2017, 19, 22454-22461.

(15) Zhang, L.; Lepper, M.; Stark, M.; Menzel, T.; Lungerich, D.; Jux, N.; Hieringer, W.; Steinrück, H.-P.; Marbach, H. On the critical role of the substrate: the adsorption behaviour of tetrabenzoporphyrins on different metal surfaces. Phys. Chem. Chem. Phys. 2017, 19, 20281-20289.

(16) Otero-Irurueta, G.; Martínez, J. I.; Bueno, R. A.; Palomares, F. J.; Salavagione, H. J.; Singh, M. K.; Méndez, J.; Ellis, G. J.; López, M. F.; Martín-Gago, J. A. Adsorption and coupling of 4-aminophenol on $\operatorname{Pt}(111)$ surfaces. Surf. Sci. 2016, 646, 5-12.

(17) Bebensee, F.; Svane, K.; Bombis, C.; Masini, F.; Klyatskaya, S.; Besenbacher, F.; Ruben, M.; Hammer, B.; Linderoth, T. Adsorption and dehydrogenation of tetrahydroxybenzene on $\mathrm{Cu}(111)$. Chem. Commun. 2013, 49, 9308-9310.

(18) Åvec, M.; Merino, P.; Dappe, Y. J.; González, C.; Abad, E.; Jelínek, P.; Martín-Gago, J. A. Van der Waals interactions mediating the cohesion of fullerenes on graphene. Phys. Rev. B: Condens. Matter Mater. Phys. 2012, 86, 1-5.

(19) Sánchez-Sánchez, C.; Dienel, T.; Nicolä, A.; Kharche, N.; Liang, L.; Daniels, C.; Meunier, V.; Liu, J.; Feng, X.; Müllen, K.; et al. On-Surface Synthesis and Characterization of Acene-Based Nanoribbons Incorporating Four-Membered Rings. Chem. - Eur. J. 2019, 25, 12074-12082.

(20) Fritton, M.; Otte, K.; Björk, J.; Biswas, P. K.; Heckl, W. M.; Schmittel, M.; Lackinger, M. The influence of ortho -methyl substitution in organometallic self-assembly-a comparative study on $\mathrm{Cu}(111)$ vs. $\operatorname{Ag}(111)$. Chem. Commun. 2018, 54, 9745-9748.

(21) Otero, R.; Gallego, J. M.; De Parga, A. L. V.; Martín, N.; Miranda, R. Molecular self-assembly at solid surfaces. Adv. Mater. 2011, 23, 5148-5176.

(22) Ruiz del Árbol, N.; Palacio, I.; Otero-Irurueta, G.; Martínez, J. I.; de Andrés, P. L.; Stetsovych, O.; Moro-Lagares, M.; Mutombo, P.; Svec, M.; Jelínek, P.; et al. On-Surface Bottom-Up Synthesis of Azine Derivatives Displaying Strong Acceptor Behavior. Angew. Chem., Int. Ed. 2018, 57, 8582-8586.

(23) Giannozzi, P.; Baroni, S.; Bonini, N.; Calandra, M.; Car, R.; Cavazzoni, D.; Ceresoli, D.; Chiariotti, G. L.; Cococcioni, M.; Dabo, I.; et al. QUANTUM ESPRESSO: a modular and open-source software project for quantum simulations of materials. J. Phys.: Condens. Matter 2009, 21, 395502.

(24) Lewis, J. P.; Jelínek, P.; Ortega, J.; Demkov, A. A.; Trabada, D. G.; Haycock, B.; Wang, H.; Adams, G.; Tomfohr, J. K.; Abad, E.; et al. Advances and applications in the FIREBALL ab initio tight-binding molecular-dynamics formalism. Phys. Status Solidi B 2011, 248, 19892007.

(25) Blanco, J. M.; González, C.; Jelínek, P.; Ortega, J.; Flores, F.; Pérez, R. First-principles simulations of STM images: From tunneling to the contact regime. Phys. Rev. B: Condens. Matter Mater. Phys. 2004, $70,1-9$.

(26) Gonzalez, C.; Snijders, P. C.; Ortega, J.; Perez, R.; Flores, F.; Rogge, S.; Weitering, H. H. Formation of Atom Wires on Vicinal Silicon. Phys. Rev. Lett. 2004, 93, 2-5.

(27) Björk, J.; Matena, M.; Dyer, M. S.; Enache, M.; Lobo-Checa, J.; Gade, L. H.; Jung, T. A.; Stöhr, M.; Persson, M. STM fingerprint of molecule-adatom interactions in a self-assembled metal-organic surface coordination network on $\mathrm{Cu}(111)$. Phys. Chem. Chem. Phys. 2010, 12, 8815-8821.

(28) Lin, N.; Dmitriev, A.; Weckesser, J.; Barth, J. V.; Kern, K. Realtime single-molecule imaging of the formation and dynamics of coordination compounds. Angew. Chem., Int. Ed. 2002, 41, 47794783.

(29) Solomon, J. L.; Madix, R. J.; Stöhr, J. Orientation and absolute coverage of benzane, aniline, and phenol on $\operatorname{Ag}(110)$ determined by NEXAFS and XFS. Surf. Sci. 1991, 255, 12-30.

(30) Olivieri, G.; Cossaro, A.; Capria, E.; Benevo, L.; Coreno, M.; De Simone, M.; Prince, K. C.; Kladnik, G.; Cvetko, D.; Fraboni, B.; et al. Intermolecular Hydrogen Bonding and Molecular Orbital
Distortion in 4 Hydroxycyanobenzene Investigated by $\mathrm{X}$ ray Spectroscopy. J. Phys. Chem. C 2015, 119, 121-129.

(31) Zou, S.; Schatz, G. C. Line shapes and satellites in highresolution x-ray photoelectron spectra of large $\pi$-conjugated organic molecules. J. Chem. Phys. 2004, 121, 10260.

(32) Mendes, P.; Belloni, M.; Ashworth, M.; Hardy, C.; Nikitin, K.; Fitzmaurice, D.; Critchley, K.; Evans, S.; Preece, J. A Novel Example of X-Ray-Radiation-Induced Chemical Reduction of an Aromatic Nitro-Group-Containing Thin Film on $\mathrm{SiO}_{2}$ to an Aromatic Amine Film. ChemPhysChem 2003, 4, 884-889.

(33) Graf, N.; Yegen, E.; Gross, T.; Lippitz, A.; Weigel, W.; Krakert, S.; Terfort, A.; Unger, W. E. S. XPS and NEXAFS studies of aliphatic and aromatic amine species on functionalized surfaces. Surf. Sci. 2009, $603,2849-2860$

(34) Ederer, J.; Janos, P.; Ecorchard, P.; Tolasz, J.; Stengl, V.; Benes, H.; Perchacz, M.; Pop-Georgievski, O. Determination of amino groups on functionalized graphene oxide for polyurethane nanomaterials: XPS quantitation vs. functional speciation. RSC Adv. 2017, 7, 12464-12473.

(35) Ravi, S.; Zhang, S.; Lee, Y. R.; Kang, K. K.; Kim, J. M.; Ahn, J. W.; Ahn, W. S. EDTA-functionalized KCC-1 and KIT-6 mesoporous silicas for $\mathrm{Nd} 3+$ ion recovery from aqueous solutions. J. Ind. Eng. Chem. 2018, 67, 210-218.

(36) Hawaldar, R.; Merino, P.; Correia, M. R.; Bdikin, I.; Grácio, J.; Méndez, J.; Martín-Gago, J. A.; Singh, M. K. Large-area highthroughput synthesis of monolayer graphene sheet by Hot filament thermal chemical vapor deposition. Sci. Rep. 2012, 2, 2-10.

(37) Ihm, H.; White, J. M. Stepwise Dissociation of Thermally Activated Phenol on Pt(111). J. Phys. Chem. B 2000, 104, 6202-6211.

(38) Bowker, M.; Madix, R. J. XPS, UPS and thermal desorption studies of alcohol adsorption on $\mathrm{Cu}(110)$ : I. Methanol. Surf. Sci. 1980, 95, 190-206.

(39) Bürgi, T.; Atamny, F.; Schlögl, R.; Baiker, A. Adsorption of Ethyl Pyruvate on $\mathrm{Pt}(111)$ Studied by XPS and UPS. J. Phys. Chem. B 2000, 104, 5953-5960.

(40) Plashkevych, O.; Yang, L.; Vahtras, O.; Agren, H.; Petterson, L. G.M. Substituted benzenes as building blocks in near-edge X-ray absorption spectra. Chem. Phys. 1997, 222, 125-137.

(41) Stöhr, J.; Outka, D. A. Determination of molecular orientations on surfaces from the angular dependence of near-edge $x$-rayabsorption fine-structure spectra. Phys. Rev. B: Condens. Matter Mater. Phys. 1987, 36, 7891-7905.

(42) Xi, M.; Yang, M. X.; Jo, S. K.; Bent, B. E.; Stevens, P. Benzene adsorption on $\mathrm{Cu}(111)$ : Formation of a stable bilayer. J. Chem. Phys. 1994, 101, 9122-9131.

(43) Liu, A. C.; Stöhr, J.; Friend, C. M.; Madix, R. J. A critical interpretation of the near-edge X-ray absorption fine structure of chemisorbed benzene. Surf. Sci. 1990, 235, 107-115. 